\title{
A IMPORTÂNCIA DAS FEIRAS LIVRES E SEUS IMPACTOS NA AGRICULTURA FAMILIAR
}

\author{
THE IMPORTANCE OF STREET MARKET FAIRS AND THEIR IMPACTS ON \\ FAMILY FARMING
}

\begin{abstract}
Francislene de Fátima Carvalho- francarvalhooo@ hotmail.com
Selma de Fátima Grossi- grossi.selma@gmail.com

Faculdade de Tecnologia de Taquaritinga (FATEC) -SP -Brasil
\end{abstract}

DOI: 10.31510/infa.v16i2.665

\begin{abstract}
RESUMO
A agricultura familiar tem como objetivo em seu sistema de produção a diversificação de cultura que permite aos produtores a obtenção de alimentos e renda os doze meses do ano. Esse segmento de produção é significativo devido a sua função ambiental, econômica e social tornando-se imprescindível para produtores familiares, pois é por meio desta que ocorre a venda e agregação do valor no produto. Como valor agregado refere-se aos produtos derivados da sua produção original, como doces, verduras lavadas e embaladas, produtos artesanais e utensílios que contribuíram com a renda da família. Os produtores rurais deparam com inúmeras dificuldades nesse elo. Sendo assim, a escolha do canal de distribuição para a venda dos produtos pelos produtores familiares, passa a ser, um fator essencial para a estratégia de comercialização. Nesse contexto, uma das alternativas de comercialização que os produtores familiares estão abraçando são as feiras-livres.
\end{abstract}

Palavras-chave: Agricultura Familiar. Feiras Livres. Desenvolvimento Local

\begin{abstract}
Family farming has as its objective in its production system the diversification of culture that allows producers to produce food and income the twelve months of the year. This segment is of significant production due to its environmental, economic and social function. Trade in agricultural and agroindustrialized products are essential for family producers, because it is through this that the sale and aggregation of value in the product occurs. Rural producers face numerous difficulties in this link. Therefore, the choice of the distribution channel for the sale of products by family producers becomes an essential factor for the strategy. In this context, one of the marketing alternatives that family producers are embracing is the free fairs.
\end{abstract}

Keywords: Family farming. Free fairs. Local Development. Socioeconomic Development 


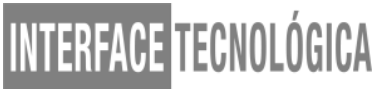

\section{INTRODUÇÃO}

Segundo a Secretaria de Agricultura Familiar e Cooperativismo (2016), a agricultura familiar tem uma grande importância para a economia nacional, pois ela está mais presente nas mesas dos brasileiros que se imagina, ela é responsável pelo leite, café, trigo, arroz, feijão, milho, suíno, mandioca, aves e ovos. Ainda de acordo com a pesquisa, no Brasil existem aproximadamente 4,4 milhões de estabelecimentos familiares, e sua maior parte está concentrado no Nordeste. A agricultura familiar está presente em $90 \%$ dos municípios brasileiros e, também responde por $35 \%$ do produto interno bruto nacional; e absorve $40 \%$ da população economicamente ativa do país.

A maior parte dos produtos agrícolas são comercializados em forma in natura assim caracterizados como um produto perecível. Por serem produtos de curta validade precisa-se de distribuição e comercialização rápida. A Agricultura familiar possui vários canais para comércio dos produtos, a saber: supermercado, restaurantes, açougues, padarias, vendas institucionais para o governo através dos programas: Programa de Aquisição de Alimentos/ PAA, Programa Nacional de Alimentação Familiar/ PNE e as feiras livres/ feira do produtor familiar. Porém, decorrente de vários fatores (barganha, perecibilidade, logística) que afetam de forma direta e indireta a renda dos produtores, a estratégia adotada foi usar um canal de comercialização com contado direto ao consumidor e sem intermediários, assim as feiraslivres tornou-se um dos principais canais para distribuição e comercialização de alimentos da agricultura familiar.

As feiras do Produtor familiar ou Feira da Agricultura Familiar - existem diversas variações no nome- é um evento que possibilita trocas de conhecimento, contatos e o principal, a negociação. A maior porcentagem dos feirantes e agricultores formam barracas para comercialização de produtos agrícolas que podem ser in natura (hortaliças, legumes) até processados (doces de frutas, geleias, queijos, entre outros).

As feiras têm como objetivo associar todos os pequenos e médios produtores agropecuários que desejam comercializar de forma atrativa os produtos: hortifrutigranjeiros, conservas, doces, produtos derivados do leite e da industrialização artesanal, artigos oriundos do artesanato, cultura e lazer e outros gêneros alimentícios.

As feiras dos produtores rurais contribuem, expressivamente, para preservar a autonomia dos produtores, aumentos de rendas, diminuição do êxito rural, desenvolvimento 


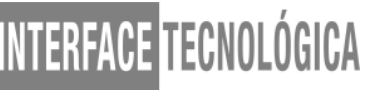

da agricultura local de forma sustentável, aumenta o valor agregado dos produtos e diminui o poder de barganha dos supermercados, mercearias, restaurantes entre outros.

Analisando o elo final - os consumidores -, as feiras asseguram soberania e a segurança alimentar, pois os consumidores finais têm conhecimento de informações, onde e como os alimentos foram produzidos, quais foram os produtos químicos ou orgânicos utilizados e o tipo de sistema de produção.

\section{OBJETIVO DO TRABALHO}

Os produtores rurais deparam com inúmeras dificuldades nesse ponto final onde entregar sua produção. Sendo assim, a escolha do canal de distribuição para a venda dos produtos, pelos produtores familiares, passa a ser, um fator essencial para a estratégia de comercialização. Nesse contexto, uma das alternativas de comercialização que os produtores familiares estão abraçando são as feiras-livres.

\section{AGRICULTURA FAMILIAR NO BRASIL}

Na contextualização da agricultura os homens (nômades) viviam da caça e coleta para se manter, realizavam o uso dessas práticas para obter seu alimento, logo passaram a utilizar o meio ambiente como forma de subsistência. Posterior a esse período configurou- se a dita revolução agrícola, onde o homem passou a cultivar seu próprio alimento, aderindo técnicas de agricultura e passando a domesticar animais para desta forma poder consumi-los adiante (BAPTISTA, 2010).

Ao longo dos anos a população começou a crescer em um nível maior ao do abastecimento de alimentos. Conforme relata Baptista (2010) que no período da Revolução Industrial o crescimento da população foi elevado, e a mecanização foi importante para uma agricultura mais eficiente, permitindo a produção em larga escala com o objetivo de atender a demanda de alimento dessa população no momento. Esse período modificou notoriamente o modo de subsistência aderido na pré-história, passando assim para uma exploração intensificada e abusiva dos recursos naturais, para obter produção em larga escala.

Para maximizar a produção foram adotados os pacotes tecnológicos americano, que marcou a fase Revolução Verde, que tinha como intuito ampliar a produção e produtividade. Entretanto os efeitos ambientais e sociais foram muito nocivos, ainda podendo ser notado 


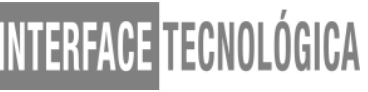

atualmente. A revolução verde proporcionou aumento da produtividade, mas vinculado a ela vieram, exploração abusiva dos recursos naturais, contaminação de solos, água e ar, problemas de saúde aos produtores, êxodo rural, desemprego - devido às máquinas que ocuparam o lugar da mão de obra rural- surgimento de novas pragas e doenças.

Diante ao cenário resultado pela revolução verde é imprescindível à configuração de um novo sistema agrícola que levasse na sua essência o eixo social, eixo sustentável e eixo econômico. De acordo com Azevedo e Nunes (2013), logo após a esse período catastrófico principiou um novo tipo de agricultura, cujo nome é agricultura familiar, que tinha como lógica suprir algumas necessidades rurais sociais e produzir os alimentos com métodos menos impactantes ao meio ambiente.

A agricultura familiar tem como objetivo em seu sistema de produção a diversificação de cultura que permite aos produtores produção de alimentos e renda os doze meses do ano. Esse segmento de produção é significativo devido a sua função ambiental, econômica e social. Ambientalmente, a maneira de utilização da terra pode ter efeitos positivos ou nocivos ao meio ambiente; referente os aspectos econômicos, a agricultura familiar atua como uma atividade de sobrevivência das famílias, sendo fonte de trabalho e renda, com relação ao quesito social ela pode certificar a melhoria na qualidade de vida das pessoas (CHIARELLO, ORLOWSKI, WACKULICZ, 2008).

De acordo com Ministério do Desenvolvimento Agrário (MDA) (2018) a agricultura familiar é protagonista no abastecimento de alimentos, essa atividade produz cerca de $87 \%$ da mandioca, $70 \%$ do feijão, $46 \%$ do milho, $38 \%$ do café, $34 \%$ do arroz e $21 \%$ do trigo, já na pecuária é responsável por $60 \%$ da produção de leite, além de $59 \%$ do rebanho suíno, 50\% das aves e $30 \%$ dos bovinos do país.

A agricultura familiar é reconhecida pela presença do produtor como sujeito central e pelo fundamental papel na produção de alimentos, enfatizando o desenvolvimento social das famílias que usam dessa herança. Ela se confronta a relação capitalista de produção em larga escala para geração de lucro, que preza acima de tudo, a dimensão econômica. 


\subsection{Canais de comercialização da agricultura familiar.}

Segundo Novaes (2001), o canal de distribuição é a reunião de organizações, agente e instituições, que podem ser do ambiente interno ou externo, que tem como intuito efetuar atividades do departamento de marketing de produtos e serviços de uma empresa.

Conforme Coughlan at al., (2002) o canal de distribuição é dividido em dois tipos que são: Distribuição direta: essa forma de distribuição ocorre sem o intermédio de outra pessoa jurídica, nesse canal a distribuição concentra-se em venda direta, marketing direto, internet, entre outros.

Distribuição indireta: tem como protagonista para distribuição o atacadista e/ou varejista.

De acordo com Deimling e Braz (2007), estes tipos de distribuição têm três ramificações tais como:

\footnotetext{
- Intensiva: O objetivo principal é colocar seus produtos em qualquer ponto de venda que possa comercializá-lo. É comumente empregado na distribuição de bens de conveniência.

- $\quad$ Seletiva: Leva-se em conta a imagem do produto. O ponto de venda deve ser compatível com a imagem do produto. É comumente empregado para bens de médio ou alto valor unitário.

- Exclusiva: é empregada quando se quer preservar ao Maximo a imagem do produto. É comumente utilizada na comercialização de bens de especialização e alguns bens de alto valor unitário, Deimling e Braz, p.3, 2007.
}

Os produtos agropecuários industrializados possuem inúmeras características diferentes, e diante disso é fundamental que a comercialização atenda cada peculiaridade. No caso dos produtos agrícolas a maioria é perecível (frutas, hortaliças), com isso a forma de comercialização deve levar em consideração logística curta e venda direta ao consumidor (AZEVEDO e FAULIN, 2005).

Segundo Moura et al., (2005), no Brasil, os canais de comercialização de alimentos são os hipermercados, supermercados, lojas de especialidades (açougues, padarias, varejões, quitandas, restaurantes), mercearias e feiras-livres.

$\mathrm{Na}$ agricultura familiar os produtores podem utilizar vários canais de distribuição e comercialização. Alguns comercializam os produtos através de supermercados, restaurantes e vendas institucionais (Programas do Governo, PRONAF, PNE e PAA). Entretanto, muitos 


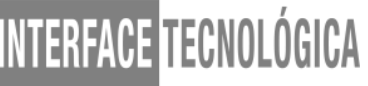

pequenos e médios produtores estão optando por outro canal de distribuição, devido a alguns fatores nos outros canais como: poder de barganha, oscilação na demanda, burocracia nos programas do Governo (chamada públicas), baixa renda, entre outros. Diante desses fatores as feiras livres tornaram-se atrativas para os produtores.

As feiras livres são um grande varejo, porém com ausências de lojas físicas, geralmente a formação das feiras ocorrem em vias públicas (praças e avenidas) e dias estabelecidos pela prefeitura e associação de produtores. A feira-livre é um canal que possibilita o contato direto entre o produtor e o cliente final, assim é possível reconhecer mais fácil as necessidades e desejos do consumidor (DEIMLING E BRAZ, 2007). Corroborando Michellon, Molina, Costa (2009), relatam que as feiras se tornam um ponto mais atrativo em relação aos supermercados e frutarias em decorrência da maior diversidade, do produto ser mais fresco, da dinâmica peculiar de negociação do preço e o atendimento personalizado, permitindo assim uma relação bastante próxima com o produtor feirante.

\section{PROCEDIMENTOS METODOLÓGICOS}

A princípio foram levantados dados bibliográficos sobre agricultura familiar com base em artigos, livros, revistas e sites.

\section{RESULTADOS E DISCUSSÃO}

O comércio de produtos agropecuários e agroindustrializados são imprescindíveis para produtores familiares, pois é através deste que ocorre a venda e agregação de valor do produto. Os produtores rurais deparam com inúmeras dificuldades nesse elo, devido a fatores como: a) poder de barganha do mercado comprador, b) perecibilidade. Para comercialização de produtos agropecuários oriundos da agricultura familiar existem quatro formas de classifica- lós, a saber, a) venda direta ao consumidor, b) integração vertical com o agronegócio processador, c) vendas para o setor de distribuição e d) mercados institucionais.

Sendo assim, a escolha do canal de distribuição para a venda dos produtos, pelos produtores familiares passam a ser, um fator essencial para a estratégia de comercialização. Nesse contexto, uma das alternativas de comercialização que os produtores familiares estão abraçando são as feiras-livres também chamada de feira agrícola, feira do produtor, feira da agricultura familiar. As feiras livres são tradicionais na maioria das regiões brasileiras. Nelas 
vende-se de tudo um pouco, conforme os produtos típicos de cada localidade, permitindo aos produtores venderem sua produção de hortifrutigranjeiros sem a interferência de terceiros, ou seja, não há intermediários nesse processo, existindo um canal direto de comercialização entre produtor e consumidor.

As feiras livres são consideradas pontos de vendas, que permite que cada produtor instale uma banca em local pré-estabelecido por algum órgão público, para comercialização dos produtos diretamente ao consumidor. A comercialização dos produtos na feira permite aos produtores feirantes a agregação de valor na mercadoria, entretanto visando um preço acessível aos consumidores e também com mais garantia de qualidade nutricional. As feiras agrícolas existem em todo o Brasil, desde os pequenos até os grandes municípios e os produtos que mais são comercializados são hortaliças e legumes, e produtos típicos da localidade da feira. Esse evento também permite aos produtores a comercialização de sua produção hortifrutigranjeira, e a intervenção de terceiros é inexistente, ou seja, não existem atravessadores, mas sim um canal direto de comercialização entre produtor e consumidor.

Os agricultores familiares que possuem comércio na feira agrícola, dispõem de um relacionamento mais direto com os consumidores, com isso ocasiona uma ligação social e oportunidades de negociações entre ambos. Corroborando Santos et al.,(2014), relata que relacionamento direto entre o feirante e o consumidor oportuniza a redução dos custos de comercializações, assim estabelecendo que as feiras se situem como canais potencialmente mais eficientes, a fim de enriquecer uma aproximação e a troca de saberes entre os agricultores- agricultores e agricultores- consumidores. Ressalta Pereira et al., (2017) que a feira do produtor é um importante canal de comercialização para a agricultura familiar, em que mostra -se uma verdadeira rede de relações instituindo dela um lugar social de trocas não somente de materiais, porém também, imateriais (sociais, históricos e culturais).

Esses eventos abrangem espaços públicos e lugares de interação em que diferentes entidades como a comunitária, a religiosa, a familiar e a societária se relacionam entre si de modo recíproco, acarretando assim um imensurável potencial para a reprodução social. De acordo com Santo et al (2014), as feiras mostram-se um lugar de conservação das relações socioculturais, dos pontos peculiares ao ambiente rural, da autonomia do/a agricultor/a e da consolidação da cultura e do saber local. Ainda de acordo com os autores, a importância da feira também aparece na conjunção de abastecimento de produtos de características locais, além de baratos e saudáveis assegura a soberania e a segurança alimentar, porque o 


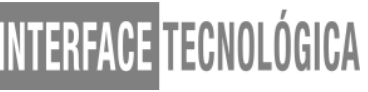

consumidor sabe o local em que os alimentos foram produzidos e a segurança é garantida no valor acessível, na diversidade e no uso quase que nulo de agroquímicos, contribuindo assim para o desenvolvimento local sustentável.

\section{CONSIDERAÇÕES FINAIS}

A agricultura percorreu inúmeras modificações, que refletiram nocivamente nos pequenos produtores, entretanto esses fatos permitiram o surgimento de uma nova agricultura, com intuito de fortalecer produtores. A agricultura familiar tem uma renda reduzida quando comparada a uma renda de agricultores empresárias (monoculturas) que produzem em maior escala. Uma maneira que os produtores têm de aumentar a renda é diversificando a produção para comercializar diferentes produtos. Porém os estabelecimentos familiares enfrentam dificuldades para colocar o que produzem no mercado, decorrente do poder de barganha e perecibilidade dos produtos. Diante desses fatos a estratégia que estas parcelas de produtores encontram para comercializar sua produção foi através das feiras.

Pode se concluir que a feira do produtor familiar é uma estratégia eficiente para os pequenos produtores de base familiar, pois permite a comercialização dos produtos com valor agregado, levando em consideração os aspectos culturais, sociais e econômicos. A feira mostrou ser um canal de distribuição com características divergentes dos outros formatos varejistas e sua escolha leva em consideração o indicador relacionado a fatores climáticos, sazonalidade do produto, preços dos produtos e regularidade da oferta.

\section{REFERÊNCIAS}

AZEVEDO, M. B. A.; NUNES, E. M.; As Feiras Da Agricultura Familiar: Um Estudo Na Rede Xique Xique Nos Territórios Açu-Mossoró E Sertão Do Apodi. Geo, Pau dos Ferros, Rio Grande do Norte, Brasil, v 3, n. 2(3), p. 59-74, jul./dez., 2013

AZEVEDO, P. F.; FAULIN, E. J. Comercialização na agricultura familiar. In: SOUZA FILHO, H. M.; BATALHA, M. O. (Orgs.). Gestão integrada da agricultura familiar. São Carlos: Edufscar, 2005

BAPTISTA, V. F. A relação entre o consumo e a escassez dos recursos naturais: uma abordagem histórica. Saúde \& Ambiente em Revista, Duque de Caxias, v.5, n.1, p.08-14, jan./jun. 2010 


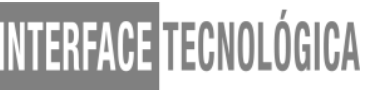

CHIARELLO, M.; ORLOWSKI, R. F.; WACKULICZ, G. J. Feiras livres: uma alternativa de geração de renda aos agricultores familiares de Chapecó (SC). In: Encontro de Economia Catarinense, 2, 2008. Anais... Chapecó, SC: APEC, 2008

COUGHLAN, A. T. et al. Canais de marketing e distribuição. 6 ed. Porto Alegre: Bookman, 2002. 461 p.

DEIMLING,M.F. BRAZ,R.J. Os canais de distribuição da agricultura familiar para a comercialização de seus produtos: o caso da região de Chapecó/SC. 2007. Disponível em:< https://www.aedb.br/seget/arquivos/artigos07/881_artigo\%20-

\%20Agricultura\%20Familiar\%20SEGET2007.pdf>. Acesso em: 21 jun, 2019.

MICHELlON, E.; MOLINA, E.C,; COSTA, T.R.; Feira do Produtor Rural Pela Visão dos Consumidores. In: V EPC Encontro Internacional de Produção Científica Cesumar, 2009.

MINISTÉRIO DO DESENVOLVIMENTO AGRÁRIO (MDA). Disponível em:< http://siater.mda.gov.br/>. Acesso em: 11 nov, 2019.

MOURA, T. T.; SILVA, A. L.; VIANA, A. B. N. Formatos de varejo: o caso do consumidor de alimentos. In: DE ANGELO, C. F.; SILVEIRA, J. A. G. (Orgs.). Varejo Competitivo. São Paulo: Saint Paul, 2005. v. 10.

NOVAES, A. G. Logística e gerenciamento da cadeia de distribuição: estratégia, operação e avaliação. Rio de Janeiro: Campus, 2001.

SANTOS, M.S.;FERREIRA,J. D.; SANTOS LEAL,R.; A Feira Livre Como Alternativa De Geração De Renda Para Agricultura Familiar No Município De Santo Estevão- Ba. In:

Estudios Territoriales, VI Congreso Iberoamericano de Estudios Territoriales y Ambientales. São Paulo, 8 a 12 de setembro de 2014.

SECRETARIA DE AGRICULTURA FAMILIAR E COOPERATIVISMO. Disponível em:< http://www.agricultura.gov.br/acesso-a-informacao/institucional/quem-e-quem/secretaria-deinovacao-desenvolvimento-rural-e-irrigacao>. Acesso em: 11 nov, 2019.

PEREIRA, V.G.; BRITO,T.P.; PEREIRA BORGES, S; A Feira-Livre Como Importante Mercado Para A Agricultura Familiar Em Conceição Do Mato Dentro (Mg). Revista

Ciências Humanas. UNITAU, Taubaté/SP - Brasil, v. 10, edição 20, Dezembro 2017 